\title{
Educação de jovens e adultos e o planejamento de carreira no CESEC Divinópolis - MG
}

Youth and adult education and career planning at CESEC Divinópolis - MG

Corina Alves Farinha ${ }^{1}$, Tânia Nogueira Fonseca Souza²

1 Universidade do Estado de Minas Gerais Unidade Divinópolis, Departamento das Engenharias, Brasil, $\quad$ E-mail: $\quad$ corina.farinha@gmail.com ORCID: https://orcid.org/0000-0003-4411-8409

2 Universidade do Estado de Minas Gerais Unidade Divinópolis, Departamento das Engenharias, Brasil, E-mail: tnfsouza@gmail.com ORCID: https://orcid.org/0000$\underline{0002-2862-5999}$

ART ICLE INFO

Article history:

Received 2020-12-29

Accepted 2021-05-04

Available online 2021-05-04
Palavras-chave: Educação. Trabalho. EJA. Planejamento de carreira.

Keywords: Keyword list. Separated by dot. Initial capital letter. Three to five keywords.

RESUMO. Trata-se do resultado de um Projeto de Extensão entre a Universidade do Estado de Minas Gerais - Divinópolis e o Centro Estadual de Educação Continuada CESEC. Objetivou-se sensibilizar um grupo de jovens e adultos para a importância de estruturar um projeto de vida profissional, elaborando plano de carreira. Aplicou-se um questionário para conhecer o público alvo. Os dados de 69 estudantes de EJA indicam: $54 \%$ adultos, de 25 a 60 anos; $46 \%$ jovens, 15 a 24 anos; $51 \%$ gênero feminino, $51 \%$ brancos, $54 \%$ não trabalham; $37 \%$ não concluíram os estudos no tempo estabelecido pelo MEC em virtude da atividade laboral e família, e 35\% por desinteresse; $41 \%$ escolheu a formação ágil do CESEC, $58 \%$ retomaram os estudos para capacitar-se; e após o CESEC $51 \%$ desejam graduar-se. Considera-se impacto na sociedade a possibilidade de contribuir para a reflexão e construção do plano de carreira de sujeitos cuja trajetória de vida pessoal e profissional abarca saberes diversos. Os estudantes do CESEC explicitaram a importância da atividade para constituir o futuro profissional; diretor, docentes e funcionários consideraram importante a atuação da Universidade pública no ambiente escolar do CESEC levando os estudantes de EJA a refletir sobre estudo, trabalho e profissão. Os graduandos relataram a relevância de conhecer e analisar a trajetória de vida pessoal e profissional de sujeitos que se esforçam para retomar os estudos, o entusiasmo e a valorização da educação para conquistar um emprego e exercer a cidadania.

ABSTRACT. This is the result of an Extension Project between the State University of Minas Gerais - Divinópolis and the State Center for Continuing Education - CESEC. The objective was to sensitize a group of young people and adults to the importance of structuring a professional life project, elaborating a career plan. A questionnaire was applied to get to know the target audience. Data from 69 EJA students indicate: 54\% 
adults, aged 25 to $60 ; 46 \%$ young, 15 to 24 years old; $51 \%$ female, $51 \%$ white, $54 \%$ do not work; $37 \%$ did not complete their studies within the time established by MEC due to work and family activities, and 35\% due to lack of interest; $41 \%$ chose agile training at CESEC, 58\% resumed their studies to train themselves; and after CESEC $51 \%$ wish to graduate. Impact on society is considered to be the possibility of contributing to the reflection and construction of the career plan of individuals whose personal and professional life trajectory encompasses diverse knowledge. CESEC students explained the importance of the activity to constitute the professional future; the director, teachers and employees considered the performance of the public university in CESEC's school environment to be important, leading EJA students to reflect on study, work and profession. The undergraduates reported the relevance of knowing and analyzing the personal and professional life trajectories of individuals who strive to resume their studies, their enthusiasm and the appreciation of education in order to win a job and exercise citizenship.

\section{Introdução}

Este trabalho é o resultado de um Projeto de Extensão, Planejamento de Carreira: construção coletiva de projeto de vida profissional tutelado pela Universidade do Estado de Minas Gerais - UEMG - Unidade Divinópolis - MG - Edital PROINPE 1/2019, realizado na unidade do Centro Estadual de Educação Continuada - CESEC Dr. Fábio Botelho Notini, sediada em Divinópolis - MG. O objetivo foi sensibilizar um grupo de jovens e adultos para a importância de estruturar um projeto de vida profissional, por meio da elaboração de um plano estruturado de carreira. O estudo buscou responder à seguinte questão: Qual é o objetivo do discente de EJA do CESEC Fábio Botelho Notini - Divinópolis - MG ao completar a sua formação? Supôsse que o grupo pesquisado apontaria a busca por emprego como projeto de vida pessoal e profissional. Todavia, os dados indicam que $51 \%$ dos respondentes pretendem graduar-se afirmando que a educação do CESEC os levou a entender que eles podem ir além do curso fundamental.

Os estudos sobre carreira, sobretudo, em ambiente de transformação auxiliam pessoas e organizações a compreender, em maior profundidade, o contexto em que estão inseridos. Plano de carreira é definido por Oliveira (2009) como a explicitação formal de um conjunto planificado, estruturado, sustentado e sequencial de estágios que consolidam a realidade evolutiva de cada indivíduo, de forma interativa com as necessidades da empresa e das comunidades onde elas atuam. Assim, o Plano de carreira deve ser formal e escrito de forma que possa ser revisto, ampliado e melhorado se tornando algo dinâmico. A equipe extensionista foi composta por duas docentes, duas graduandas em Engenharia Civil e três em Comunicação Social Jornalismo. O projeto foi realizado em três encontros. A equipe salientou aos participantes, a relevância da elaboração explícita do plano de carreira, acompanhando o preenchimento, dirimindo dúvidas, auxiliando a reflexão sobre carreira profissional numa perspectiva de projeto de vida pessoal.

Para conhecer o público atendido aplicou-se um questionário. Os dados de 69 estudantes de EJA indicam: 37 (54\%) adultos, de 25 a 60 anos; 32 (46\%) jovens, 15 a 24 anos. Dos 69, 35 (51\%) gênero feminino, 35 (51\%) brancos, 37 (54\%) não trabalham; 26 (37\%) não concluíram os estudos no tempo estabelecido pelo MEC em virtude da atividade laboral e família e 24 (35\%) por desinteresse; 28 (41\%) escolheu o CESEC para estudar devido à rápida formação; 37 (58\%) retomaram os estudos 
para capacitar-se; e após o CESEC 35 (51\%) desejam graduarem-se. Considera-se impacto na sociedade a possibilidade de contribuir para a reflexão e construção do plano de carreira de sujeitos cuja trajetória de vida pessoal e profissional abarca saberes diversos. Os estudantes do CESEC explicitaram a importância da atividade para constituir o futuro profissional; diretor, docentes e funcionários destacaram a atuação da Universidade pública no ambiente escolar do CESEC levando os estudantes de EJA a refletir sobre estudo, trabalho e profissão. Os graduandos relataram o impacto na sua formação ao conhecer e analisar a trajetória de vida pessoal e profissional de sujeitos que se esforçam para retomar os estudos, bem como, o entusiasmo e a valorização da educação para conquistar um emprego e exercer a cidadania.

\section{Desenvolvimento}

Destaca Hollanda (2002) que a melhoria das condições sociais e culturais de uma coletividade está atrelada à estreita relação entre educação, capacidade produtiva e o emprego. Nesse sentido, ações afirmativas governamentais, como a Educação de Jovens e Adultos - EJA permite o acesso a jovens, adultos e idosos retomar os estudos e qualificar-se. Um dos locais em que a EJA é disponibilizada é o Centro Estadual de Educação Continuada - CESEC. Trata-se de uma escola semipresencial integrante da Rede Estadual de Ensino atendendo aos jovens e adultos que não concluíram o Ensino Fundamental elou Médio no período estabelecido pelo Ministério da Educação e Cultura - MEC. O CESEC oferece cursos desenvolvidos em regime didático de matrícula por componente curricular (disciplina) ou conjunto de componentes curriculares, incluindo momentos presenciais e não presenciais.

Por outro lado, a Universidade do Estado de Minas Gerais - UEMG, Instituição de Ensino Superior ${ }^{1}$ foi criada em 1989, por disposição contida na Constituição do Estado. É uma universidade multicampi presente em 16 municípios do Estado de Minas Gerais e 20 unidades, oferecendo 118 cursos de graduação (presencial e Ensino a Distância), pós-graduação 27 Lato Sensu, 8 mestrados e 2 doutorados. A Unidade Divinópolis oferece 17 cursos de graduação presencial, 6 cursos de pósgraduação presencial e um na modalidade a distância.

A Universidade do Estado de Minas Gerais - UEMG tem sido agente do setor público junto às comunidades, colaborando na solução de seus problemas, através do ensino, da pesquisa e da extensão e na formatação e implantação de seus projetos de desenvolvimento, conforme descreve o Projeto Pedagógico do curso de Engenharia Civil $^{2}$ - PPC (2015). A missão universitária da UEMG expressa a consciência da indissociabilidade entre ensino, pesquisa e extensão. Em sintonia com este princípio, o curso de Jornalismo ${ }^{3}$, procura estabelecer parcerias que possam resultar em trabalhos interdisciplinares, requisito fundamental para uma formação acadêmica que perpassa diversos campos do conhecimento. Busca-se gerar este diálogo por meio das disciplinas de graduação e projetos de pesquisa e extensão que tenham relação com o campo da comunicação e a atividade do Jornalismo, realizados tanto por docentes do curso quanto por docentes de outros cursos da instituição, que contam, também, com a participação dos discentes como bolsistas ou voluntários. Nesse âmbito, entende-se que os educadores, educandos, pesquisadores e gestores devem buscar os caminhos que articulem as alternativas de melhoria de condição de

\footnotetext{
https://www.uemg.br

2 http://www.uemg.br/graduacao/cursos2/course/engenharia-civil

3 http://www.uemg.br/images/PPC_Jornalismo_Divinopolis_aprovado_conun_23.06.16.pdf
} 
vida da sociedade como um todo. O educador/professor universitário não pode se ater às suas especialidades, se esquecendo de que faz parte de um contexto educacional maior que urge por iniciativas que possam minimizar a extensa diferença social e de formação em suas diversas modalidades.

Da mesma forma, o aluno que emerge da Universidade, além da formação tecnológica, deve estar, durante sua formação, inserido em programas, projetos e atividades nas quais possam adquirir a capacidade crítica - reflexiva, com visão holística e conscientes da sua importância no contexto social. O graduando deve ampliar sua percepção e se tornar um profissional capaz de transformar o ambiente, buscando a melhoria das condições de vida do homem sendo capaz de atuar em equipes multidisciplinares.

Nesse contexto de possibilidade de análise da mudança social, de inserção de professores e alunos no ambiente educacional, além dos muros da Universidade, propicia-se o estabelecimento de uma visão e de meios para se transformar realidades. Assim, entende-se que este trabalho ao adotar metodologia de plano de carreira contribui na busca de informações que levem a análises, e a novos projetos de intervenção. Tais elementos justificaram a realização do projeto de extensão no CESEC.

\subsection{Educação de Jovens e Adultos - EJA}

A Educação é garantida a todos os brasileiros pela Constituição Federal ${ }^{4}$, conforme Art. 208, e pela Lei de Diretrizes e Bases da Educação Nacional - LDB, № $9.394^{5}$. A Educação de Jovens e Adultos é uma modalidade de ensino, amparada por lei e voltada para pessoas que não tiveram acesso, por algum motivo, ao ensino regular na idade apropriada. A EJA tem como funções: reparar, qualificar e equalizar o ensino abrangendo os mais diversos processos de formação - continuada e permanente, formais e informais - perpassando quase todos os espaços de convívio social. A EJA traz para o ambiente escolar uma diversidade de perfis e de demandas individuais de pessoas que abandonaram, evadiram ou simplesmente não conseguiram concluir sua escolarização.

Dados do Inep ${ }^{6}$ indicam que no Brasil entre 2014 e 2018 há 15.455 jovens aos 17 anos fora da escola. Pesquisas em torno do tema, como de Ajala (2011) abordam os motivos de abandono e retorno escolar e expectativas pós EJA em Santa HelenaPR citando que o EJA é pela maioria uma modalidade e visa somente à conclusão do ensino básico. Entretanto, uma parcela significativa do público anseia a continuação dos estudos aspirando uma melhora futura. Santos (2003) relaciona as causas do abandono da escola regular às dificuldades provocadas pelo próprio sistema educacional, pelas limitações pessoais e limitações familiares afirmando que muitas pessoas interrompem os estudos para ajudar no sustento da família. Na pesquisa realizada por Lima (2008) 51\% dos alunos têm de 25 a 55 anos sendo $53 \%$ sexo feminino. Em relação ao retorno à escola as razões com maiores porcentagens foram: exigência do mercado de trabalho $49 \%$, realização pessoal $40 \%$, saber lidar com novas tecnologias $23 \%$.

Arroyo (2007) aborda o preparo para o trabalho: a capacitação para a empregabilidade, os saberes sobre o trabalho e das muitas formas de capacitar para o trabalho para tornar os discentes competentes. O mundo está cada vez mais

\footnotetext{
${ }^{4}$ http://www.planalto.gov.br/ccivil_03/constituicao/constituicao.htm

5 http://www.planalto.gov.br/ccivil_03/leis/19394.htm

${ }^{6}$ https://novaescola.org.br/conteudo/15467/censo-escolar-educacao-basica-perde-13-milhao-de-alunos-em-quatro-anos
} 
competitivo, em função dos processos de produção seletiva, é preciso desenvolver a competência para o trabalho. Isto significa levar o discente a entender os saberes dos mundos do trabalho, os quais são mais do que as competências para enfrentar um concurso ou um emprego. Pois o desemprego é um dos traços dos discentes de EJA, trabalhando informalmente, subempregados num contexto de sobrevivência mais imediata. É preciso projetar um futuro diferente da configuração de um trabalhador dependente daquilo que aparece para ganhar a vida, intervindo no presente.

Cabe ressaltar que Freire (2000) ensina o respeito aos saberes dos educandos indicando que a docência ao salientar as experiências de vida dos discentes deve construir um processo educativo para além da codificação e decodificação de aspectos linguísticos, para que os discentes façam uso social e político dos saberes na vida cotidiana. Ou seja, num contexto de condições de verdadeira aprendizagem os educandos devem se transformar em reais sujeitos da construção e da reconstrução do saber ensinados, construindo trajetórias significativas e autônomas.

\subsection{Centro Estadual de Educação Continuada - CESEC Divinópolis MG.}

O Projeto Político e Pedagógico da Unidade (2018) e o regimento interno da instituição ${ }^{7}$ explicitam uma política educacional baseada na oferta de uma educação escolar para jovens, adultos e idosos, com características adequadas às suas necessidades, garantindo-se aos que forem trabalhadores as condições de acesso e permanência na escola como consta na LDB, Art. $4^{\circ}$. A modalidade de ensino Educação de Jovens e Adultos - EJA é intercalada de momentos presenciais e não presenciais, e as matrículas acontecem por módulos disciplinares, e ao final da conclusão de todos os módulos, o discente conclui o Ensino Fundamental, anos finais e/ou o Ensino Médio. As matrículas estão abertas durante o ano todo. Para o Ensino Fundamental a idade é 15 anos e para o Ensino Médio a idade mínima de 18 anos completos. Na EJA, não há enturmação como acontece nas escolas regulares. A frequência diária do estudante não é obrigatória, entretanto, ele deverá cumprir a carga horária de 16 horas por componente curricular, possuindo flexibilidade quanto ao tempo para estudos e liberdade para fazer sua própria organização curricular e executar o Plano de Estudos, devendo obter nota não inferior a $50 \%$ em cada um dos 6 módulos. Além da modalidade Educação de Jovens e Adultos, o CESEC Fábio Botelho Notini ainda oferece certificações por aproveitamento de estudos em exames SUPLETIVO, ENEM, ENCEJA, TELECURSO 2000, ou outros equivalentes e a Banca Permanente de Avaliação, cujo funcionamento iniciou a partir 02/09/2002. Nesta escola os turnos de atendimento são vespertino e o noturno. No turno matutino funciona apenas serviço de natureza administrativa e não há atendimento externo. Em 2016 contava com 2.728 discentes, início de outubro do ano de 2018, o número de matrículas chegou a 2.666 estudantes. A infraestrutura escolar é insuficiente. Não há sala de aula para atender todos os componentes curriculares que constam na legislação do CESEC. No entanto, há sala de informática e biblioteca. As condições de acessibilidade da estrutura arquitetônica para estudantes com deficiência são inadequadas, mas estão previstas adequações no projeto de reforma da escola, obra que até já fora licitada em dezembro de 2016. Apresenta quadro de profissionais: diretor, secretário, 01 especialista em educação básica, 22 professores orientadores de aprendizagem, 06 assistentes técnicos de educação básica, 6 auxiliares de serviços de educação básica, 01 professor na biblioteca e 01 servidor em ajustamento funcional. Os funcionários atuam em funções de direção, departamento pessoal, secretaria do curso, biblioteca, cantina, coordenação pedagógica, salas de aula, sala

${ }^{7}$ Disponibilizado pela instituição via e-mail 
de professores, banca permanente de avaliação e sala de avaliação da banca permanente de avaliação.

De acordo ainda com o PPP (2018) da unidade, a demanda atendida pela escola é composta, em grande parte, por estudantes trabalhadores, o que é um dificultador quanto a uma participação mais efetiva deles no planejamento da escola. A percepção, por parte dos estudantes, a respeito da segurança no interior e no exterior da escola é bastante positiva. Tal fato se deve por não constar registro de violência na escola e os poucos conflitos que surgem entre professor/a e/ou funcionários/as e estudantes são resolvidos com bastante diálogo. A composição de gênero e étnico-racial da instituição é em sua grande maioria composta por pessoas do sexo feminino e branca. Mais de $90 \%$ dos professores são habilitados (formação acadêmica adequada) nos componentes curriculares que lecionam e especialistas na área pedagógica. A escola conta com uma parte da equipe de professores que nunca trabalhou na instituição. A estabilidade da equipe tem sido comprometida pelo fato da adoção de uma política da Secretaria de Estado de Educação de impedir a movimentação de servidores efetivos para escola. Soma-se a isso, o fato de muitos funcionários terem se aposentado nos últimos 2 anos. Os profissionais são experientes nas diferentes redes de ensino.

\subsection{Planejamento de carreira}

Dutra (2002) adota o conceito de carreira de London e Stumph (1982) e afirma que a carreira envolve a ocorrência de transições ligadas às necessidades individuais e imposições da organização e da sociedade. Para os autores, a carreira nada mais é do que um conjunto de posições ocupadas por um indivíduo no trabalho durante a vida. Além disso, colocam-na como uma sequência de estágios e transições, cujas variações estão ligadas às pressões originadas no ambiente e, inclusive, no próprio indivíduo.

Para Dutra (2009) os estudos sobre a carreira são importantes em um ambiente de transformação, pois auxiliam trabalhadores e organizações a compreender em maior profundidade a realidade em que vivem. A recomendação visa minimizar equívocos que podem significar sofrimento e perdas, riscos e prejuízos para indivíduos e organizações. A reflexão sobre a carreira deve ir além da identificação de oportunidades profissionais, das estruturas existentes nas empresas ou no mercado de trabalho, da sucessão de cargos ou posições no organograma.

Segundo Dutra (2002) a tendência de entender a trilha profissional como algo dado e a falta de estímulo para elaboração de um plano de carreira levam as pessoas a não realizar autoavaliação quanto a interesses e potencial para vários espaços organizacionais. No entanto, em momentos de crise e escassez de empregos levamnas a procurar conselhos, métodos e instrumentos que as ajudem no processo. Um plano de carreira estruturado contribui para análise e construção de um perfil profissional a ser confrontado com as demandas organizacionais e possibilidades de ações empreendedoras. Um plano de carreira proporciona posicionamento consciente quanto à trajetória profissional.

Oliveira (2009) apresenta uma metodologia para elaboração e aplicação de um plano estruturado de carreira, no qual, contempla seis fases analíticas: mercado atual e futuro; vocação e capacitação profissional; estabelecimento de vantagem competitiva; objetivos e estratégias; código de ética profissional e evolução profissional. Estas fases são divididas em subfases visando o aprofundamento sobre os temas conforme Quadro 1 - Plano de Carreira. 


\section{Quadro 1 - Plano de Carreira}

\section{Etapas}

1.1 O que você quer para seu futuro pessoal e profissional?

1.2 Quais são seus valores, princípios, crenças pessoais?

1.3 Quais as oportunidades e ameaças?

$1.4 \mathrm{O}$ que pode acontecer no futuro, com as oportunidades e ameaças existentes?

\section{Etapas}

2.1 Qual é a sua vocação (talento) profissional?

2.2 Qual a sua habilidade em aprender e aplicar conhecimentos

profissionais?

Pontos fortes características positivas

Pontos fracos características a desenvolver 2.3 Qual a área do mercado você pretende trabalhar?

2.4 Qual será 0 seu comportamento ou métodos que vai utilizar, para atingir seus objetivos pessoais e profissionais?

\section{Etapa}

3.1 Quem são seus concorrentes no mercado de trabalho?

3.2 O que você tem de ponto forte que o seu concorrente não tem?

\section{Etapa}

4.1 Quais são seus objetivos /metas (etapas para alcançar o objetivo)?

4.2 De que maneira pretende atingir seus objetivos/metas?

\section{Etapa}

5.1 O que você considera como importante nas suas atitudes para alcançar seus objetivos profissionais?

\section{Fase 1 - Análise do mercado atual e futuro}

Identificação do que o indivíduo quer ser; período de tempo mais longo e abordagem mais ampla. Conjunto de princípios, crenças e questões éticas que sustentam todas as suas principais decisões.

Situações no mercado de trabalho que favorecem ou prejudicam o futuro se conhecidas e trabalhadas. Situações, critérios e medidas para a preparação do futuro.

\section{Fase 2 - Análise da vocação e capacitação} profissional

Aptidão pessoal para uma atividade específica

Habilidade de identificar, adquirir, aplicar conhecimentos na área de atuação.

Características positivas, relevantes.

Características prejudiciais, inadequadas.

Razão de ser, o que impulsiona uma pessoa a fazer alguma coisa; espaço de atuação.

Cruzamentos entre ameaças e oportunidades do mercado e pontos fortes e fracos do indivíduo.

\section{Fase 3 - Estabelecimento da diferenciação} competitiva

Identificação e conhecimento dos concorrentes no mercado de trabalho

Identificação de característica pessoal relevante

Fase 4 - Estabelecimento dos objetivos e metas

Etapas para o alcance de resultados quantificáveis com prazos para realização.

Maneiras, alternativas para alcançar os objetivos.

Fase 5 - Estabelecer código de ética profissional

Critérios orientadores do comportamento 


\begin{tabular}{|l|l|}
\hline $\begin{array}{l}5.2 \text { O que você sabe sobre o } \\
\text { código de ética profissional? }\end{array}$ & Normas de conduta profissional \\
\hline Etapa & Fase 6 - Análise da evolução profissional \\
\hline $\begin{array}{l}6.1 \quad \text { Analise o seu } \\
\text { desenvolvimento } \\
\text { profissional? }\end{array}$ & Realização do plano de carreira, desempenho. \\
\hline $\begin{array}{l}\text { 6.2 O que você pode fazer } \\
\text { para melhorar o seu } \\
\text { desenvolvimento } \\
\text { profissional? }\end{array}$ & Avaliação dos resultados, monitoramento. \\
\hline
\end{tabular}

Fonte: Adaptado de Oliveira (2009, p. 67-86)

\section{Metodologia}

Trata-se de um projeto de extensão em que foram gerados dados ao aplicar a metodologia: Plano de Carreira, de Oliveira (2009), e um questionário para conhecer o público alvo. É, assim, uma pesquisa quali-quantitativa de natureza exploratória e descritiva. O estudo é de um fenômeno atual, a inserção de estudantes da Educação de Jovens e Adultos no mundo da escola e do trabalho e a responsabilidade individual sobre a construção da carreira por meio da escrita de um plano estruturado. A pesquisa exploratória proporcionará maior familiaridade com o problema podendo torná-lo explícito e/ou construir hipóteses. As investigações desta natureza objetivam maior aproximação com o fenômeno para que seja possível familiarizar-se com as características e peculiaridades do tema a ser explorado, para obter percepções, idéias desconhecidas e inovadoras sobre os mesmos. Trata-se, também, de um estudo de caso cuja unidade de análise, CESEC Dr. Fábio Botelho Notini Divinópolis - MG, escolhida pelo critério oferta de Educação a Jovens e Adultos e o aceite da instituição para a realização do projeto. Para Collis e Hussey (2005) a pesquisa qualitativa identifica-se pelo contexto subjetivo que implica em exames e reflexões sobre os procedimentos, dados e informações para obter entendimento.

Um estudo de caso, para Yin (2005, p. 32) é "uma investigação empírica que investiga um fenômeno contemporâneo dentro de seu contexto da vida real, especialmente quando os limites entre o fenômeno e o contexto não estão claramente definidos". A unidade de análise deve estar relacionada à maneira como as questões iniciais da pesquisa foram definidas. Os sujeitos da pesquisa foram discentes matriculados na modalidade Educação de Jovens e Adultos na referida instituição. Por se tratar de um estudo exploratório, algumas limitações poderão ser observadas na análise dos resultados (YIN, 2005) como a dificuldade de generalizar dados a partir de um único estudo de caso. Porém, o objetivo é explorar e conhecer melhor a área em pesquisa, bem como destacar a importância para o indivíduo, escola e o trabalho.

Afirma Yin (2005) que os estudos de caso reúnem numerosas e detalhadas informações acerca de uma situação, podendo utilizar-se de várias técnicas de coleta de dados. A unidade de observação foi composta por dois tipos de fontes de evidências: dados primários obtidos por meio da atividade prática em sala e os dados de natureza bibliográfica sobre carreira e EJA. Assim, os dados primários foram coletados por meio de um questionário, "Quadro 2" Formulário de coleta de dados. As atividades de coleta de dados foram realizadas em três encontros em dias alternados, de acordo com a disponibilidade da diretoria do CESEC. Como não há enturmação, os dados foram coletados por meio da técnica de acessibilidade, ou seja, disponibilidade dos sujeitos de pesquisa nas datas aprazadas. Com os questionários 
preenchidos, a equipe reuniu-se e procedeu à leitura inicial dos dados, fase de préanálise (BARDIN, 2011), gerando categorias de análise relacionadas ao referencial teórico. As questões de número: 09, 11 a 15 em virtude da extensão dos dados gerados não integram este trabalho.

\section{Quadro 2 - Formulário adaptado de coleta de dados}

\begin{tabular}{|l|c|}
\hline \multicolumn{1}{|c|}{ Questões orientadoras } & \multicolumn{1}{c|}{ Respostas tabuladas } \\
\hline $\begin{array}{l}\text { 1.Motivo da interrupção dos estudos em } \\
\text { idade regular. }\end{array}$ & Tabela 2 Interrupção dos estudos \\
\hline 2.Tempo fora da Escola & Dados não inseridos neste artigo \\
\hline 3. Motivo do retorno aos estudos & Tabela 3 Planejamento de carreira \\
\hline 4. Por que escolheu o CESEC? & Tabela 2 Interrupção dos estudos \\
\hline 5.O que fará ao terminar o curso. & Tabela 3 Planejamento de carreira \\
\hline 6. Idade & Tabela 1 Perfil dos participantes \\
\hline 7. Gênero. & Tabela 1 Perfil dos participantes \\
\hline 8. Identificação étnico racial & Tabela 1 Perfil dos participantes \\
\hline 9. Tem filhos? & Dados não inseridos neste artigo \\
\hline 10. Atividade laboral & Tabela 1 Perfil dos participantes \\
\hline 11. Tipo de atividade laboral exercida & Dados não inseridos neste artigo \\
\hline 12. Renda & Dados não inseridos neste artigo \\
\hline 13. Pai e mãe estudaram até que série & Dados não inseridos neste artigo \\
\hline 14. Curso superior na família & Dados não inseridos neste artigo \\
\hline
\end{tabular}

Fonte: Os autores (2021)

\section{Resultados e discussão}

O Gráfico 1 - Perfil dos participantes apresenta a distribuição dos 69 respondentes, estratificado por faixa etária: jovens, 15 a 24 anos; adultos, 25 a 60 anos; gênero, etnialraça e atividade laboral.

\section{Gráfico 1}

\section{Perfil dos participantes}

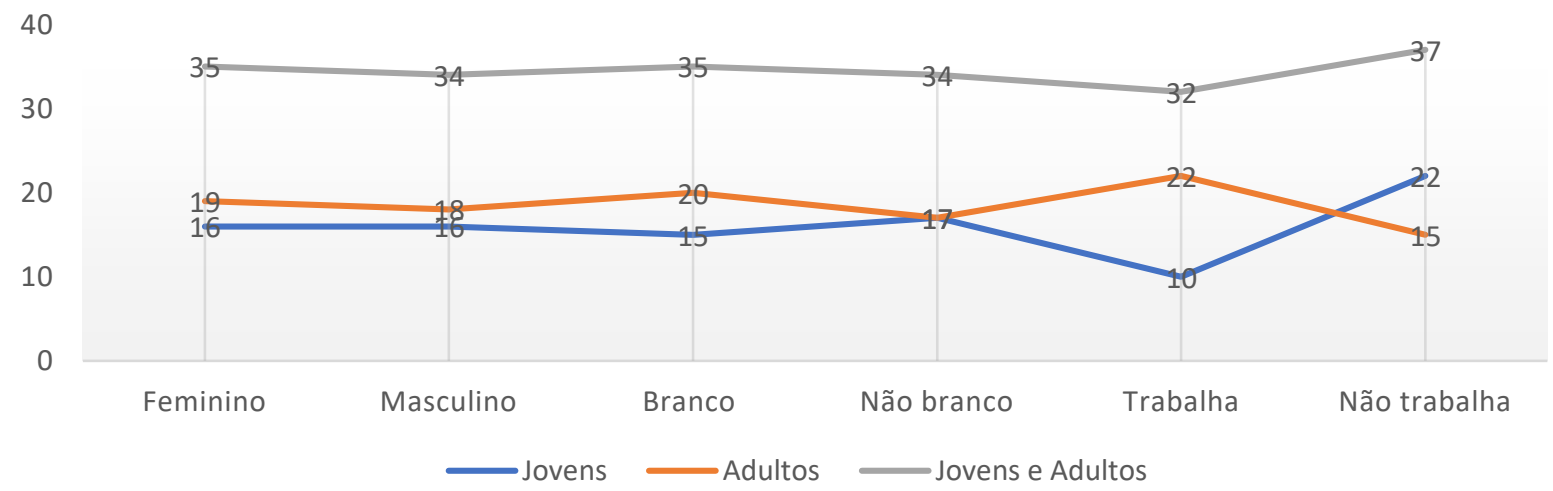

Fonte: Os autores (2019) 
Dos 69 respondentes, 32 (46\%) são jovens na faixa etária entre 15 a 24 anos e 37 (54\%) são adultos de 25 a 60 anos. Pesquisas do INEP no período entre os anos 2014 e 2018 indicam que a evasão escolar é maior entre os jovens; Lima (2008) informa que $51 \%$ dos alunos de EJA têm de 25 a 55 anos. Outra semelhança de perfil de alunos pode ser verificada na distribuição por gênero sendo $53 \%$ sexo feminino verificado na pesquisa de Lima (2008) e $51 \%$ do gênero feminino neste projeto. Os dados indicam que $51 \%$ dos participantes se identificaram como brancos confirmando os dados fornecidos pelo CESEC. A composição de gênero e étnico-racial na instituição pesquisada em sua grande maioria é composta por pessoas do sexo feminino e branca. Quanto à atividade laboral, os dados indicam que $54 \%$ dos participantes não estão trabalhando. Estes dados dialogam com a discussão de Arroyo (2007) sobre a configuração da EJA, tender a configurar-se, cada vez mais, como um projeto de educação popular dos jovens e adultos jogados à margem cujo primeiro traço é o desemprego.

\subsection{Motivos para interromper os estudos e escolha pela formação no CESEC}

O Gráfico 2 apresenta dados do Quadro 2 - Formulário de coleta de dados, item 1. Motivos da inconclusão dos estudos em idade regular e item 4. Escolha do CESEC para retomar os estudos.

\section{Gráfico 2}

\section{Interrupção dos estudos e formação no CESEC}

30

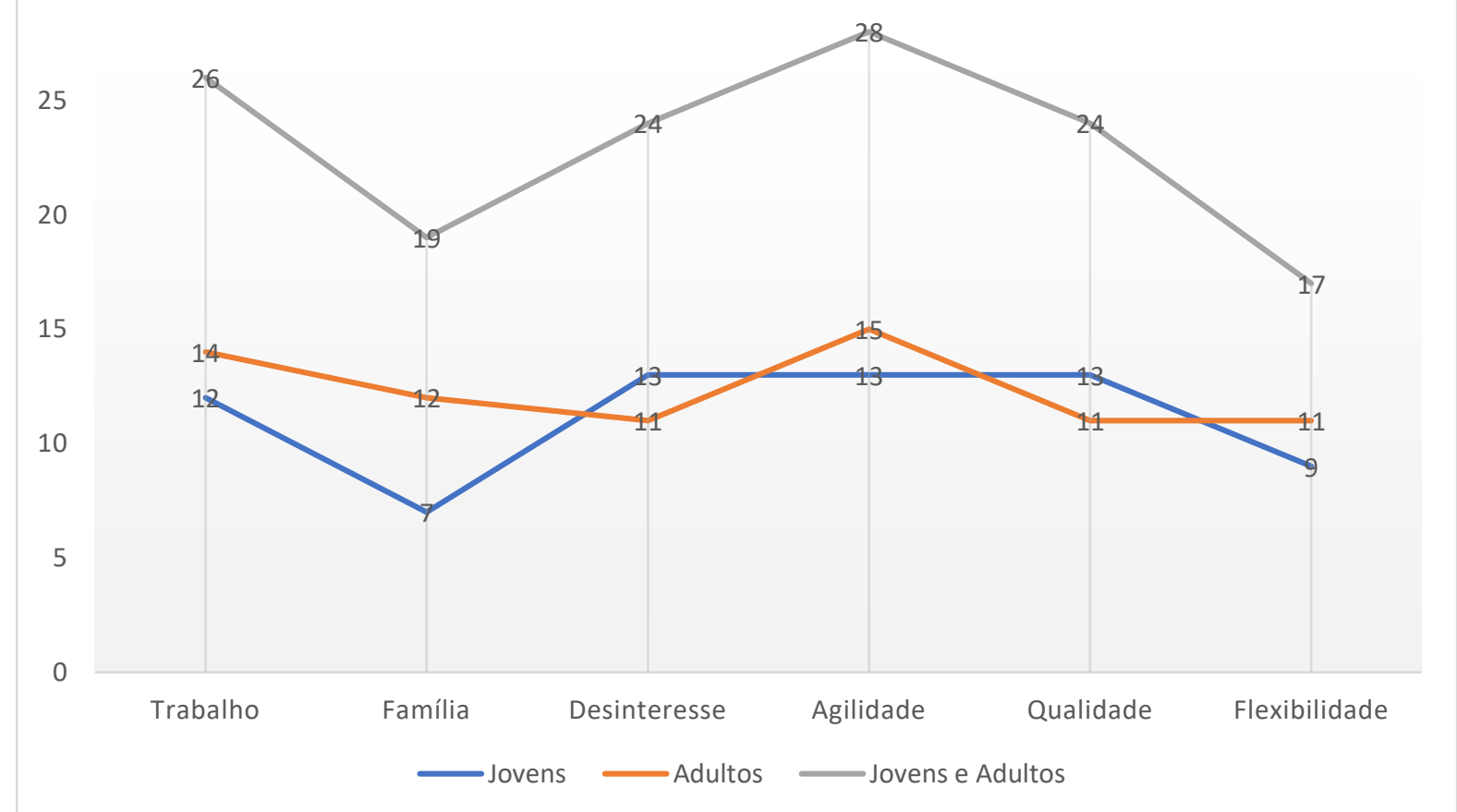

Fonte: Os autores (2021) 
Os motivos para o abandono dos estudos referem-se aos dados de 26 (37\%) dos respondentes reportando a necessidade de trabalhar e $26(37 \%)$ a aspectos ligados à família, como gravidez e doença; para 24 (35\%) relataram desinteresse. Esses resultados alinham-se aos de Santos (2003) referindo-se às causas do abandono da escola regular, as dificuldades provocadas pelo próprio sistema educacional, pelas limitações pessoais e familiares.

Os motivos de escolha da formação no CESEC relacionam-se à agilidade para conclusão dos estudos para $28(41 \%) ; 24(35 \%)$ a qualidade e para $17(25 \%)$ a flexibilidade. Estes dados traduzem a metodologia da EJA na oferta de cursos em regime didático de matrícula por componente curricular, disciplina, ou conjunto de componentes curriculares, incluindo momentos presenciais e não presenciais. A Qualidade é apontada como um elemento importante para $35 \%$ dos discentes afirmando que a escolha pela instituição foco deste trabalho devido a indicação, ao acolhimento conferido pelo diretor, corpo docente e funcionários da unidade bem como dos saberes, conteúdos das disciplinas e alimentação.

Assim sendo, tais elementos dialogam com os valores básicos da instituição como descritos no PPP fundamentados na ética, respeito, liberdade de expressão, igualdade, solidariedade, cooperação, prudência e compromisso com a instituição e comunidade escolar, para que realmente ocorra uma efetivação do processo ensinoaprendizagem.

\subsection{Planejamento de Carreira: Qual é o objetivo do discente de EJA do CESEC Fábio Botelho Notini ao completar a sua formação?}

O Gráfico 3 - Motivos para retomada dos estudos e objetivos após CESEC, refere-se aos dados da questão 3 e questão 5 do Formulário de coleta de dados, Quadro 2. Os dados visam elucidar os objetivos dos discentes ao elaborar o Plano de Carreira e a questão de pesquisa: Qual é o objetivo do discente de EJA do CESEC Fábio Botelho Notini ao completar a sua formação?

\section{Gráfico 3 \\ Motivos para retomada dos estudos e objetivos após CESEC}

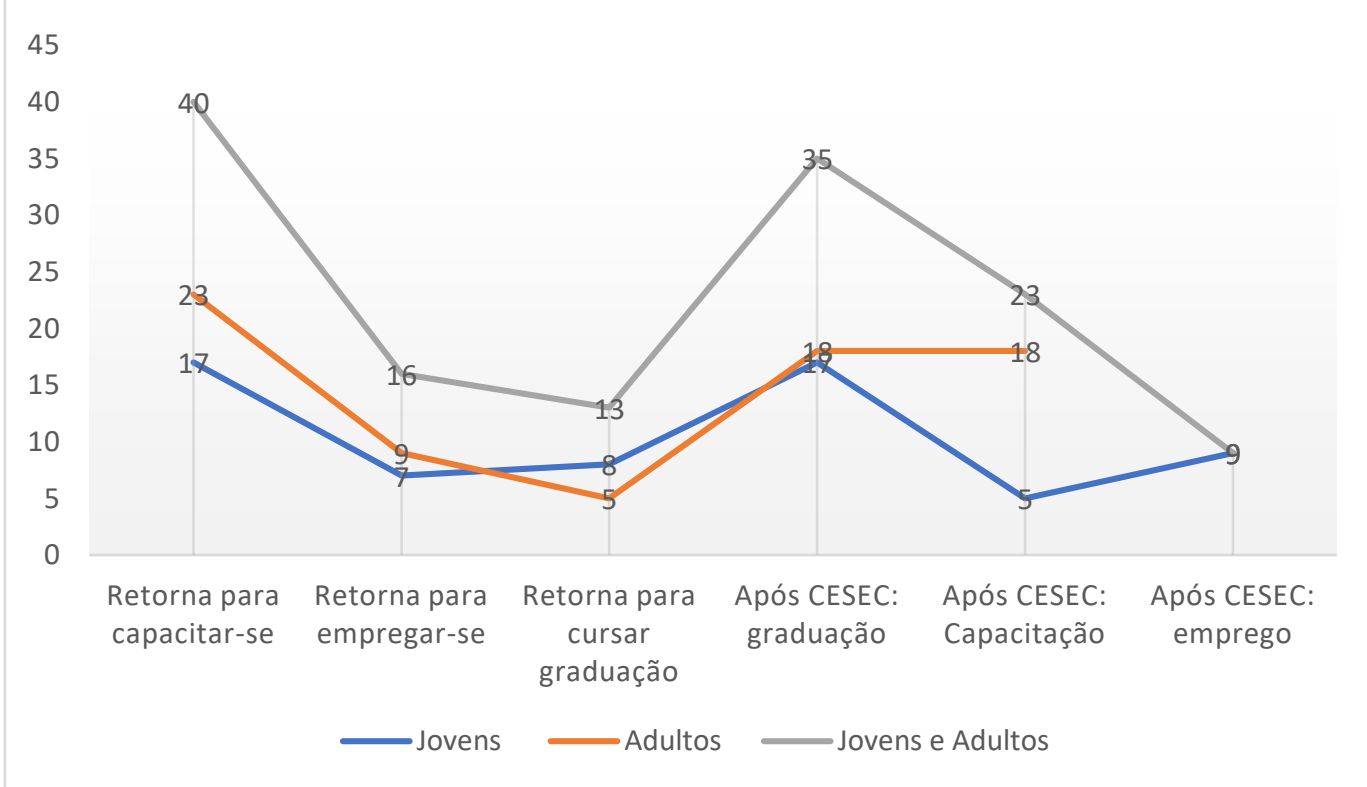

Fonte: Os autores (2021) 
Os dados indicam que para 40 respondentes (58\%) do grupo pesquisado o motivo para retornar aos estudos refere-se à capacitação profissional; 16 (23\%) visam o emprego e 13 (19\%) a graduação.

Na pesquisa de Lima (2008) $49 \%$ dos respondentes, mencionaram o retorno à escola devido às exigências do mercado de trabalho. Arroyo (2007) salienta o preparo para o trabalho citando a capacitação para a empregabilidade em virtude da competitividade, em função dos processos de produção seletiva. Ao indicar o desemprego, o trabalho informal, num contexto de sobrevivência imediata, como traços dos discentes de EJA defende a necessidade de projetação de um futuro diferente, intervindo no presente. Para tanto, são necessários saberes sobre os mundos do trabalho, defende Arroyo (2007). Nesse sentido, 19\% do grupo pesquisado retornam à escola visando à graduação, indicando como possibilidade de intervenção no presente, a EJA do CESEC Fábio Botelho Notini-Divinópolis MG.

Quanto aos objetivos após a formação do CESEC, os dados apontam que 35 respondentes (51\%) pretendem graduarem-se; 23 (33\%) capacitarem-se e 9 (13\%) buscar emprego. Isto parece indicar que a EJA ao trazer para o ambiente escolar uma diversidade de perfis e de demandas individuais de pessoas que abandonaram, evadiram ou simplesmente não conseguiram concluir sua escolarização permitiu aos estudantes do CESEC Fábio Botelho Notini - Divinópolis - MG, estabelecer um projeto de vida pessoal e profissional baseado na continuidade dos estudos por meio da graduação.

Por outro lado, compreende-se que de modo geral os discentes do EJA matriculados na instituição foco deste estudo, objetivam após a formatura, graduaremse, capacitarem-se para assim alcançar o emprego que desejam. Nesse sentido, entende-se que o objetivo do projeto de levar o público alvo à reflexão sobre a importância de estruturar um projeto de vida profissional, por meio da elaboração de um plano estruturado de carreira foi alcançado.

\section{Conclusão}

Este trabalho teve como objetivo sensibilizar um grupo de jovens e adultos para a importância de estruturar um projeto de vida profissional, por meio da elaboração de um plano estruturado de carreira. Buscou-se responder à seguinte questão central de pesquisa: Qual é o objetivo do discente de EJA do CESEC Fábio Botelho Notini Divinópolis - MG ao completar a sua formação?

Supôs-se que o grupo pesquisado indicaria a busca por emprego como projeto de vida pessoal e profissional. No entanto, os dados indicaram que $51 \%$ dos respondentes, ou seja, 35 dos 69 participantes da pesquisa pretendem graduarem-se, 23 (33\%) almejam a capacitação em alguma área de estudos e 9 (13\%), especificamente jovens, almejam empregarem-se.

A análise e interpretação dos dados permitiu concluir que o grupo pesquisado refletiu sobre planejamento de carreira apresentando etapas tendo foco nas necessidades individuais, graduação e a busca por emprego, considerando que as organizações contam com a capacitação de seus colaboradores num contexto de competitividade.

Dessa forma, por tratar-se de um projeto de extensão, considera-se impacto na sociedade a contribuição para a reflexão e construção do plano de carreira de sujeitos cuja trajetória de vida pessoal e profissional abarca saberes diversos. Os estudantes da Educação de Jovens e Adultos, EJA, explicitaram a importância da atividade para 
constituir o futuro profissional. $\mathrm{O}$ diretor, docentes e funcionários destacaram a relevância da parceria institucional com a Universidade pública para o ambiente escolar no Centro Estadual de Educação Continuada - CESEC propiciando aos estudantes a reflexão sobre a estudo, trabalho e profissão.

Além disso, para os graduandos houve impacto na sua formação, ao conhecerem e analisarem a trajetória de vida pessoal e profissional de sujeitos que se empenham para retomar os estudos, constatando o entusiasmo e a valorização da educação para conquistar um emprego e exercer a cidadania. Isto possibilitou aos discentes rever a posição que ocupam na sociedade ao estudarem numa instituição pública.

As docentes do projeto foram impactadas na medida que ao ampliar o espaço da sala de aula aos discentes de ambas as instituições compreenderam vivamente a relevância da educação como prática social transformadora de realidades.

\section{Agradecimentos}

Gratidão a todos os componentes da equipe cuja contribuição possibilitou este trabalho: nossos discentes do curso de Jornalismo e de Engenharia Civil da Universidade do Estado de Minas Gerais UEMG - Unidade Divinópolis.

Nosso muito obrigada à direção e à coordenação pedagógica do Centro Estadual de Educação Continuada - CESEC Dr. Fábio Botelho Notini Divinópolis - MG pela acolhida deste projeto desde as primeiras tratativas e em todo o processo de coleta de dados. Agradecemos a disponibilidade do corpo docente, do bibliotecário e dos funcionários em contribuir para a coleta de dados, disponibilizando materiais, lanchinhos e ambiente agradável para a equipe. Gratidão aos 69 discentes da Educação de Jovens e Adultos - EJA que se dispuseram a dialogar, trocar experiências, dividir histórias de vida pessoal e profissional as quais enriqueceram a todos os discentes e docentes.

Agradecemos à Pró-Reitoria de Pesquisa e Pós-Graduação - PROPPG da Universidade do Estado de Minas Gerais, ao Programa Institucional de Pesquisa PROINPE 1/2019 a aprovação do projeto de extensão. Agradecimento especial à equipe de pesquisa e extensão da UEMG - Unidade Divinópolis pela atenção e disponibilidade em atender às demandas da equipe deste projeto.

\section{REFERÊNCIAS}

AJALA, M. C. ALUNO EJA: motivos de abandono e retorno escolar na modalidade EJA e expectativas pós EJA em Santa Helena-PR. 2011. $45 \mathrm{f}$. Monografia (Especialização) - Curso de Educação, Diretoria de Pesquisa e Pósgraduação, Universidade Federal Tecnológica do Paraná, Medianeira, 2011. Disponível em:

<<http://repositorio.roca.utfpr.edu.br/jspui/bitstream/1/1647/1/MD PROEJA 2012 IV 16.pdf>> Acesso em: 13 mar. 2020.

ARROYO, M. Tema desenvolvido por ocasião da $67^{a}$ plenária do Fórum Mineiro de Educação de Jovens e Adultos, realizada na Faculdade de Educação da UFMG, no dia 29 de junho de 2007 , ocasião que se comemorou o 9o aniversário desse fórum. Disponível em: <<http://forumeja.org.br/go/files/Balan\%C3\%A70\%20da\%20EJA\%20\%20Arroyo.pdf >> Acesso em: 15 mar. 2020.

BARDIN, L. Análise de conteúdo. São Paulo: Edições 70. 2011 COLLIS, J.; HUSSEY, R. Pesquisa em administração: um guia prático para alunos de graduação e pós-graduação. Porto Alegre: Bookman, 2005. 
DUTRA, J. S. Gestão de carreira. In FLEURY, M. T. L. (Org.). As pessoas na organização. São Paulo: Gente, 2002.

DUTRA, J. S. Gestão de pessoas - modelo, processos, tendências e perspectivas. São Paulo: Atlas, 2009.

FREIRE, P. Pedagogia da autonomia: saberes necessários à prática educativa. 14ㄹ. ed. - São Paulo - SP : Editora Paz e Terra S/A, 2000.

HOLLANDA, N. Introdução à economia. $8^{\mathrm{a}}$ ed. Petrópolis Rio de Janeiro: Vozes, 2002.

LIMA, M. P. S. R. de. A representação social de escola para alunos e alunas da EJA - educação de jovens e adultos - de uma escola estadual que oferece esta modalidade de ensino. 2008. 145 f. Dissertação (Mestrado) - Curso de Educação, Departamento de Pós-graduação em Educação, Ufam, Manaus, 2008. Disponível em:<<https://tede.ufam.edu.br/bitstream/tede/4171/2/Disserta\%C3\%A7\%C3\%A30\% 20-\%20Maria\%20do\%20Perp\%C3\%A9tuo\%20Socorro.pdf>> Acesso em: 13 mar. 2020.

OLIVEIRA, D. P. R. Plano de carreira: foco no indivíduo. São Paulo: Atlas, 2009. SANTOS, Geovânia Lúcia dos. Educação ainda que tardia: a exclusão da escola e a reinserção de adultos das camadas populares em um programa de EJA. Rev. Bras. Educ. [online]. 2003, n.24, pp.107-125. ISSN 1413-2478. Disponível em: <<https://doi.org/10.1590/S1413-24782003000300009 >> Acesso em: 13 mar. 2020 YIN, R. K. Estudo de caso: planejamento e métodos. 3. ed. Porto Alegre: Bookman, 2005. 